\title{
An analysis of surveillance screening for SDHB-related disease in childhood and adolescence
}

\author{
Nicola Tufton ${ }^{1,2}$, Lucy Shapiro ${ }^{2,3}$, Anju Sahdev ${ }^{4}$, Ajith V Kumar ${ }^{5}$, Lee Martin ${ }^{3}$, William M Drake ${ }^{1,2}$, Scott A Akker ${ }^{1,2}$ and \\ Helen L Storr ${ }^{2,3}$ \\ ${ }^{1}$ Department of Endocrinology, St Bartholomew's Hospital, Barts Health NHS Trust, London, UK \\ ${ }^{2}$ Centre for Endocrinology, Barts and the London School of Medicine and Dentistry, Queen Mary University of London, London, UK \\ ${ }^{3}$ Department of Paediatric Endocrinology, Royal London Hospital, Barts Health NHS Trust, London, UK \\ ${ }^{4}$ Department of Radiology, St Bartholomew's Hospital, Barts Health NHS Trust, London, UK \\ ${ }^{5}$ North East Thames Regional Genetics Service, Great Ormond Street Hospital, London, UK \\ Correspondence should be addressed to H L Storr: h.l.storr@qmul.ac.uk
}

\begin{abstract}
Objective: Phaeochromocytomas (PCC) and paragangliomas (PGL) are rare in children. A large proportion of these are now understood to be due to underlying germline mutations. Here we focus on succinate dehydrogenase subunit B (SDHB) gene mutation carriers as these tumours carry a high risk of malignant transformation. There remains no current consensus with respect to optimal surveillance for asymptomatic carriers and those in whom the presenting tumour has been resected.

Method: We undertook a retrospective analysis of longitudinal clinical data of all children and adolescents with SDHB mutations followed up in a single UK tertiary referral centre. This included index cases that pre-dated the introduction of surveillance screening and asymptomatic carriers identified through cascade genetic testing. We also conducted a literature review to inform a suggested surveillance protocol for children and adolescents harbouring SDHB mutations.

Results: Clinical outcomes of a total of 38 children are presented: 8 index cases and 30 mutation-positive asymptomatic carriers with 175 patient years of follow-up data. Three of the eight index cases developed metachronous disease and two developed metastatic disease. Of the 30 asymptomatic carriers, 3 were found to have PGLs on surveillance screening.

Conclusions: Surveillance screening was well tolerated in our paediatric cohort and asymptomatic paediatric subjects. Screening can identify tumours before they become secretory and/or symptomatic, thereby facilitating surgical resection and reducing the chance of distant spread. We propose a regular screening protocol commencing at age 5 years in this at-risk cohort of patients.
\end{abstract} Key Words - SDHB

- childhood

- paediatric

- adolescents

- screening

- surveillance

- imaging

\section{Introduction}

Almost $40-50 \%$ of all phaeochromocytomas (PCC) and paragangliomas (PGL) (together known as PPGLs) are now thought to be associated with germline mutations $(1,2)$, but within the paediatric population this figure is higher
(70-80\%). Therefore, it is recommended that all children and adolescents presenting with PPGL should be offered genetic testing $(3,4)$. The most commonly associated genes in children presenting with PPGL (aged $\leq 21$ years) https://ec.bioscientifica.com

https://doi.org/10.1530/EC-18-0522

C 2019 The authors Published by Bioscientifica Ltd

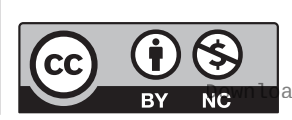

This work is licensed under a Creative Commons Attribution-NonCommercial 4.0 International License. ded from Bioscientifica.com at 04/26/2023 04:08:10AM 
are $V H L(38 \%)$, followed by SDHB (25\%), SDHD (7\%) and RET (6\%) (4). Familial PPGLs have an earlier onset (2), are more often bilateral (5) and are more likely to recur (5) when compared to sporadic tumours.

SDHB mutations are inherited in an autosomal dominant manner and have a lifetime penetrance of $30-40 \%$ (6). Individuals carrying $S D H B$ mutations command special attention as they contribute a high proportion of the PPGLs occurring in paediatric patients (3) and have a high rate (up to 30\%) of malignant transformation $(7,8)$. Approximately $72 \%$ of metastatic PPGLs in childhood are associated with SDHB mutations (3). This emphasises the importance of lifelong, regular surveillance for all children carrying $S D H B$ mutations in an experienced centre as, although hard to prove, it is generally accepted that early detection and timely resection of $S D H B$-associated tumours will reduce the risk of metastatic disease.

Despite widespread acceptance that individuals who carry SDHB mutations should undergo regular surveillance imaging, there is no clear consensus regarding the optimal modality or frequency. The situation is even less clear in paediatric $S D H B$ carriers due to the paucity of robust data, highlighted in a recent review (9). Since the discovery of $S D H B$ mutations as a cause for PPGL syndromes, increasing numbers of genetically affected young family members are being identified and referred to specialist paediatric services (2). Hence, it is important to establish an appropriate surveillance protocol specifically for paediatric carriers. This must also consider the potential long-term risks of radiation exposure at younger ages (10) and the acceptability to young patients and their carers.

To address these fundamental issues, we performed a review of the published literature. In parallel we undertook detailed analysis of our paediatric $S D H B$ cohort of both index cases and asymptomatic carriers to provide longitudinal data on clinical outcomes. Based on these combined data, we propose a regular surveillance protocol for screening children with $S D H B$ mutations.

\section{Patients and methods}

We undertook a retrospective review of paediatric $S D H B$ mutation-positive index cases and asymptomatic carriers managed in our UK tertiary referral centre. Although a subgroup of these patients have been previously described $(11,12)$, we considered that a separate analysis of this unique patient cohort was justified on account of the lack of published paediatric $S D H B$ patient data and recent new information regarding the risks of radiation exposure in young patients (10).

Paediatric index cases were diagnosed with a PCC or PGL in childhood or adolescence (aged $<20$ years) between 1975 and 2011. Index cases presented to their local endocrine centres and were followed locally until after surgical resection. Inevitably, as the majority of the index cases were diagnosed before genetic testing become readily available and pre-date the introduction of familial PPGL surveillance programmes, they were followed up as per local guidance at the time of diagnosis and some were lost to follow up for a number of years before re-presenting. Once the genetic status was established (between 2003 and 2012), the index patients underwent regular surveillance in our centre.

Asymptomatic paediatric carriers were identified through cascade genetic screening of index cases. Children whose carrier status was confirmed following genetic screening were clinically assessed by an experienced paediatric endocrinologist and offered radiological and biochemical screening.

\section{Genetic testing}

All suspected paediatric $S D H B$ carriers were offered genetic counselling and testing. This included index cases that presented with symptomatic PPGL or individuals with relatives known to carry $S D H B$ mutations. Genetic analysis in at-risk children was routinely undertaken aged $<5$ years. However, 20 children were diagnosed genetically between the ages of 5 and 18 years when their individual risk was established, following the identification of an $S D H B$ gene mutation in a family member. Five paediatric index patients presented before genetic testing was routinely available. The genetic status of these individuals was identified at a later date, usually after the development of a second tumour or metastatic disease. The median time from diagnosis of the first PPGL to the confirmation of the $S D H B$ mutation was 15 years (range $0-34$ years) in the index cases.

\section{Surveillance protocol}

Regular surveillance for $S D H$ patients was introduced in our centre in 2003, and therefore some of these index cases pre-date systematic surveillance follow-up. From 2003, paediatric patients were reviewed with other affected family members in a dedicated family SDH clinic by adult and paediatric endocrinology consultants and clinical nurse specialists. Clinical review, including auxological 
assessment, general examination, blood pressure and heart rate measurements were undertaken in all children annually. Metanephrines (urine or plasma) were measured annually from age 5 years.

\section{Biochemical testing}

24-hour urine metanephrine measurements were analysed by a high-performance liquid chromatography with electrochemical detection (HPLC-ED) assay for total fractionated metanephrines. Urine metanephrine:creatinine ratio was measured on spot urine samples. Plasma metanephrines (free fractionated) were analysed by LC-MS/MS. Age-specific reference ranges were used for spot urine metanephrine:creatinine ratio and plasma metanephrine results.

\section{Radiological imaging}

Abdominal ultrasound (US) or magnetic resonance imaging (MRI) of the neck, chest, abdomen and pelvis was performed annually, as previously described (11). The imaging was reviewed on two separate occasions as standard practice at our institution; the first radiological opinion was issued as a standard report when imaging was performed; the second was provided within a multidisciplinary meeting by an appropriate diagnostic imaging expert.

\section{Results}

Analysis included a total of 38 children (21 families): 8 index cases (4 male) and $30 \mathrm{SDHB}$ mutation-positive asymptomatic carriers (12 male) identified through cascade genetic testing. The median duration of follow-up was 5.0 years (range $0.5-13.0$ years) and 24.5 years (range 6-42 years) in the 30 asymptomatic carriers and 8 index cases, respectively. Two children were reviewed in the paediatric clinic (aged 8 and 15 years) and then lost to follow-up (after 4 and 1 year(s), respectively) and were re-referred aged 18 years. Data includes 175 patient years of follow-up initiated at either diagnosis (index cases) or the time of identification of $S D H B$ mutation carrier status.

\section{Index cases}

The index cases were diagnosed at median age 15 years (range 10-18 years) (Table 1). All presented with solitary lesions with no evidence of metastatic disease. Four had abdominal PGLs, two had thoracic PGLs, one a PCC and one had a pelvic PGL. All underwent successful surgical resection of the primary tumour. Five of the eight cases (diagnosed 1989-2011) had no evidence of further disease identified by regular surveillance scanning, with a median duration since the original diagnosis of 13.8 years (6-27 years).

The remaining three children developed multiple tumours in adulthood (including 15 further PGLs and 1 papillary renal cell carcinoma (RCC)). Two of the three patients developed disseminated metastatic disease in adulthood. The time from diagnosis to development of further disease was 7.0, 13.0 and 16.5 years, respectively. The two patients with metastatic disease died aged 35 and 41 years (Table 1 ) with a survival time of 17 and 4 years from the diagnosis of metastatic disease, respectively. Detailed clinical descriptions of the three patients that developed metachronous and/or metastatic disease are provided in the supplementary data (see section on supplementary data given at the end of this article).

\section{Asymptomatic carriers}

Thirty children were found to have $S D H B$ mutations on cascade genetic testing (Table 2). Genetic testing was undertaken at a median age of 6.8 years (range 1 month to 18.0 years) and the median age of their first clinical review was 8 years (range $1-15$ years). Five children were $<5$ years at diagnosis and underwent annual clinical review only until the age of 5 years. Seventeen were aged 5-9 years at presentation and underwent annual 24-h urine metanephrine collections, US scanning of the abdomen and full clinical assessment. Five children aged 5-9 years underwent at least one MRI in place of an abdominal US scanning. Nine patients were 10-18 years old at diagnosis and had annual MRI.

To date, 27 of the 30 asymptomatic carriers have had no tumours identified during a median follow-up period of 5 years (range 1-9 years). Three of the 30 asymptomatic carriers (at ages 15, 16 and 18 years) were found to have abdominal PGLs ( $14 \mathrm{~mm}, 65 \mathrm{~mm}$ and $11 \mathrm{~mm}$, respectively) identified on surveillance imaging (Table 2). Detailed clinical descriptions of these patients are provided in the supplementary data.

\section{Discussion}

The aim of the surveillance screening in $S D H B$ mutation carriers is to detect and manage the

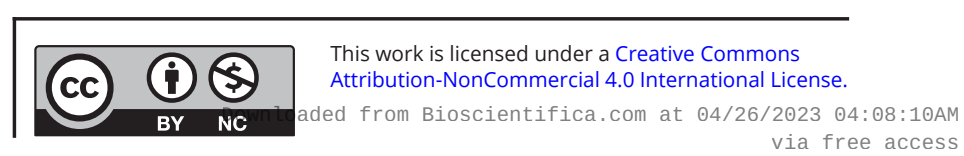




\section{Endocrine
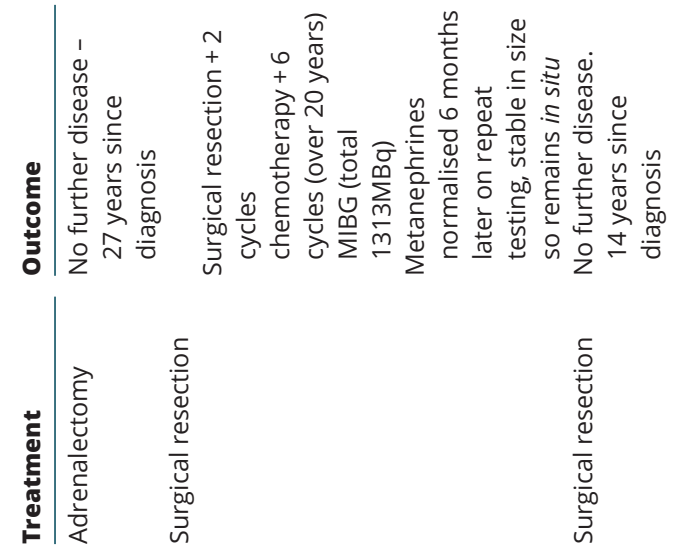

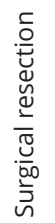

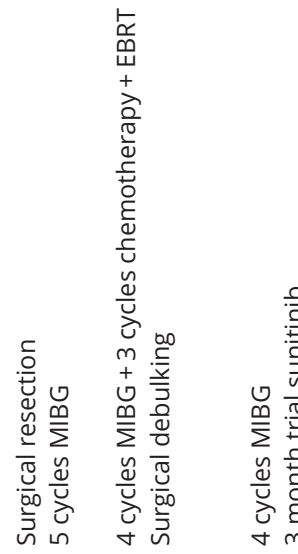

$£ \quad \bar{\sim}$
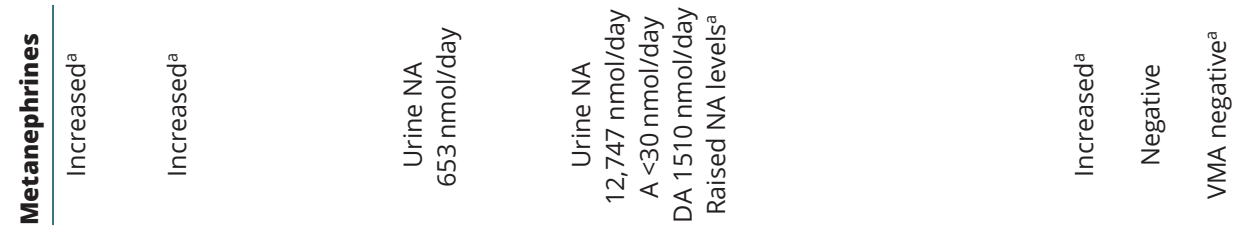

온
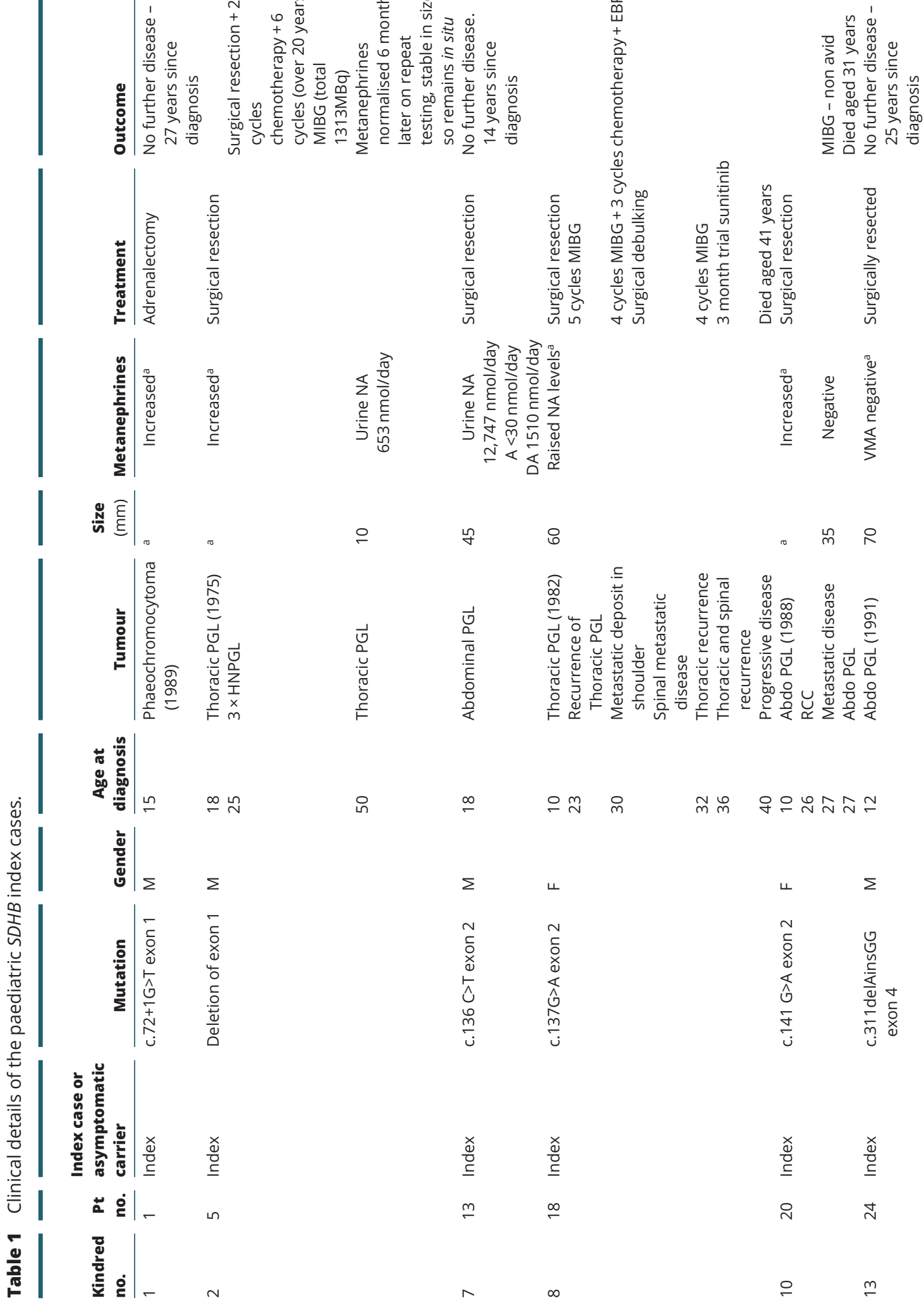

$\stackrel{\infty}{\sim}$

요

$\stackrel{\infty}{\longleftarrow}$

유 요

mํำ 운윷ำ

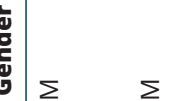

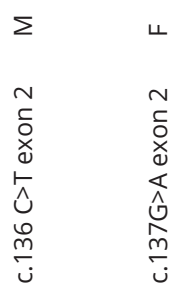

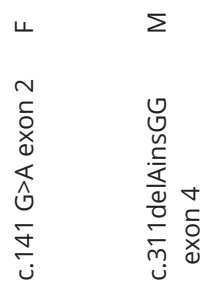

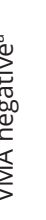




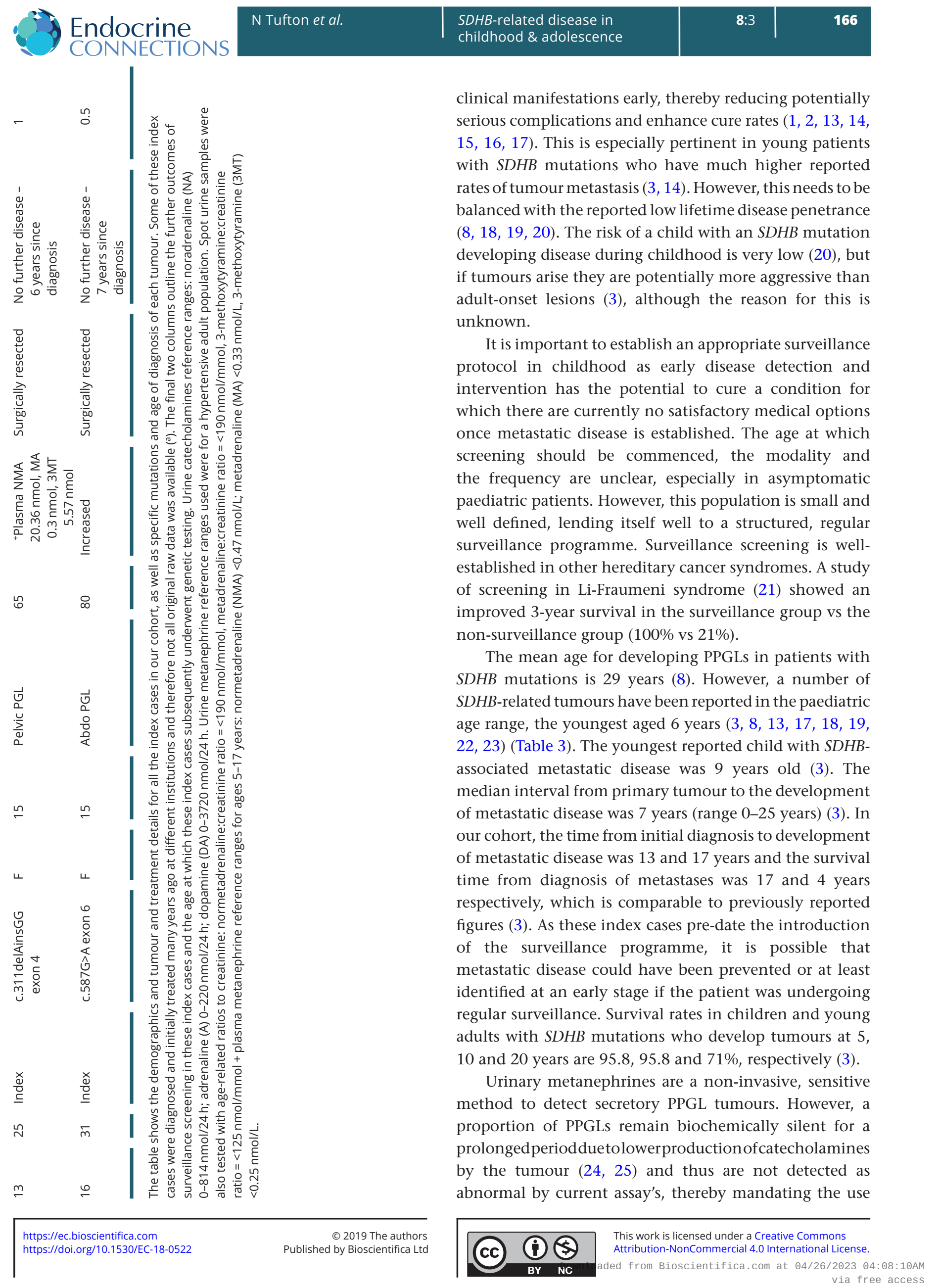




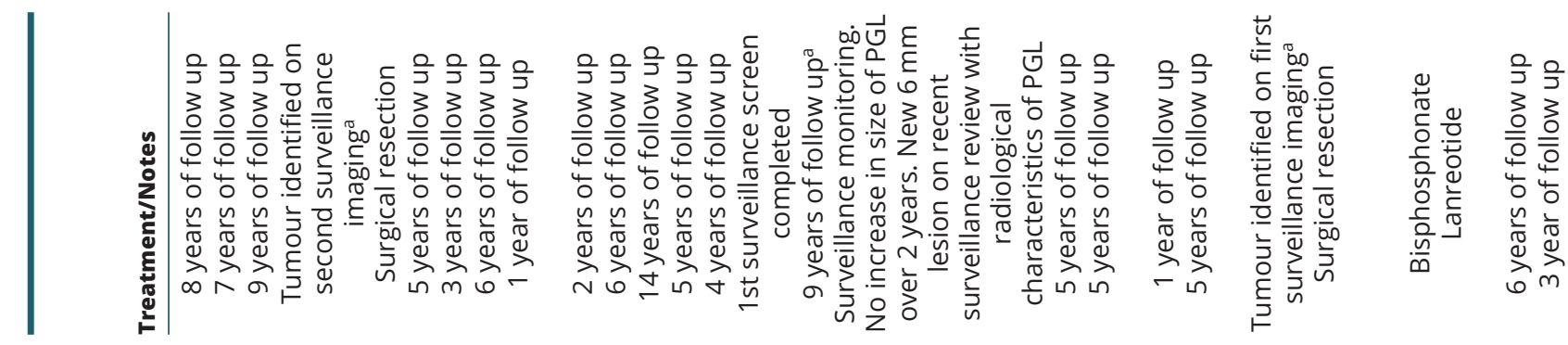

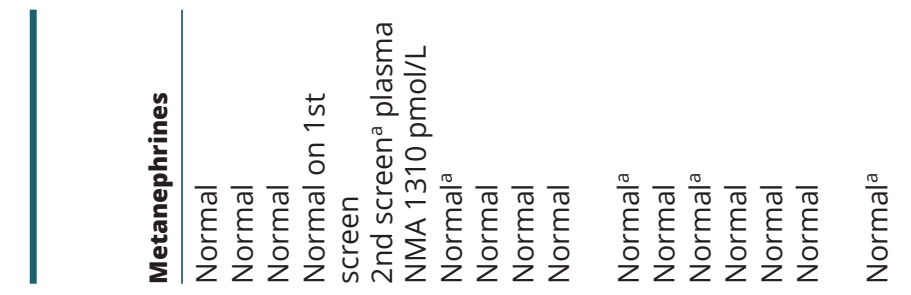

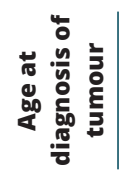

.0.

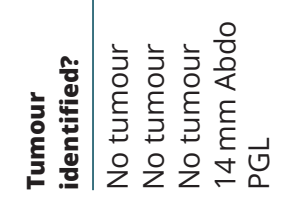

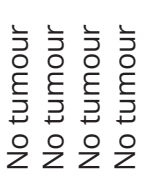

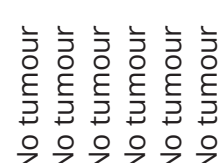

$\stackrel{\circ}{\infty} \bar{\sim}$

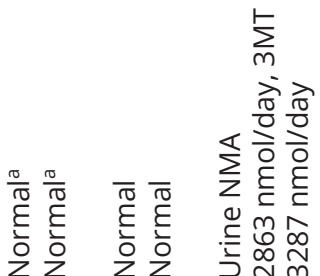

$\stackrel{\circ}{\stackrel{n}{n}}$

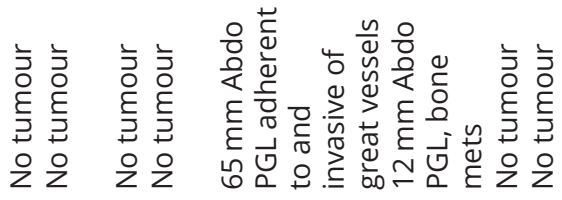

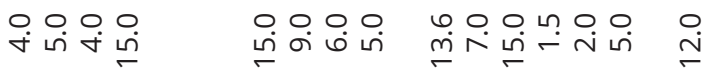

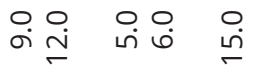

웅ํํ

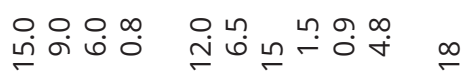

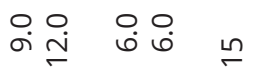

우웅

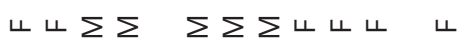

ч $\Sigma$ ч $\Sigma$

$\Sigma u$

ᄃㄷำ

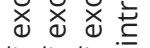

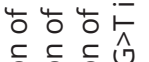

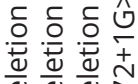

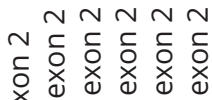

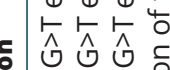

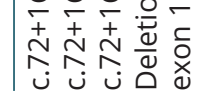

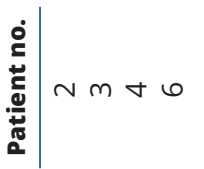

$\wedge$ ヘ윤ํㄴำ

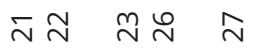

$\stackrel{\infty}{\sim}$ 

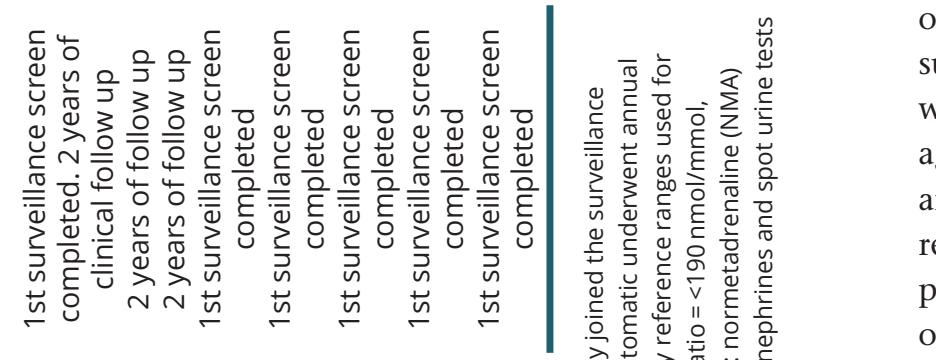

of imaging in surveillance programmes. We reviewed the suggested published surveillance protocols for patients with $S D H B$ mutations (26). Only three studies advise the age at which surveillance screening should commence and are based on data published by Benn et al. These recommend commencing surveillance at age 5-10 years, predicting that, if started by 10 years of age, $96 \%$ cases of $S D H B$-associated PGLs would be captured $(18,27,28)$. None of these articles provide specific recommendations for the modality or frequency of screening in the paediatric population. A recent review suggested surveillance should begin between ages 6 and 8 years for all hereditary PPGL syndromes, with annual clinical and biochemical review and biennial whole-body MRI $(9)$. Others $(14,17)$ advocate the necessity of surveillance screening in at-risk children but do not suggest a protocol. Eijkelenkamp et al. (29) used a more statistical approach to calculate the optimal age to commence imaging for head and neck PGL (HNPGL), in SDHB and concluded commencing at age 27 years with 3 yearly surveillance scanning, but no children were included in their cohort. Hence, there is no current consensus as to the age at which surveillance screening should commence in children nor the optimal protocol.

CT and functional imaging are undoubtedly useful in the management of PPGL-associated disorders, especially in the identification of metastatic disease, but involve the use of ionising radiation, the risks of which are hard to gauge in a cancer-prone syndrome. This is particularly relevant in children as the total lifetime risk of cancer induction is highest when radiation exposure occurs at younger ages. Clinicians and radiologists need to balance this increased risk when justifying high radiation dose investigations in children. The cumulative cancer risk for a young female aged $<20$ years following a single chest, abdomen and pelvis (CAP) CT scan is $>1$ in 1000 additional cancers. The lifetime risk of cancer incidence in children $<9$ years is estimated as $14 \%$ per Sv radiation exposure (10). These data are derived from a population without a known tumour predisposition and, although hard to prove, it is assumed that these risks will be higher in $S D H B$ patients who have a higher background risk of tumour development. In keeping with this, Schiffman et al. supports the use of total body MRI for early cancer surveillance in young patients (14). The Endocrine Society guidelines state that MRI is indicated when radiation exposure should be limited (30), which is particularly relevant in children and individuals with known germline mutations predisposing to PPGL. Additionally, one should distinguish between the surveillance of asymptomatic https://ec.bioscientifica.com https://doi.org/10.1530/EC-18-0522 (c) 2019 The authors Published by Bioscientifica Ltd
This work is licensed under a Creative Commons Attribution-NonCommercial 4.0 International License. ded from Bioscientifica.com at 04/26/2023 04:08:10AM 
Table 3 Youngest diagnosis with SDHB-related tumours.

\begin{tabular}{l}
\hline Site of PPGL \\
\hline Adrenal neuroblastoma \\
Abdominal PGL \\
Adrenal phaeochromocytoma \\
HNPGL \\
Thoracic PGL \\
Pelvic PGL \\
RCC \\
GIST (stomach) \\
Metastatic disease
\end{tabular}

\begin{tabular}{ccc}
$\begin{array}{c}\text { Age at diagnosis } \\
\text { (years) }\end{array}$ & & References \\
\cline { 1 - 1 } $\begin{array}{c}n \\
5\end{array}$ & & $(22)$ \\
9 & & $(18)$ \\
9 & & $(19)$ \\
10 & & $(11)$ \\
16 & & $(32)$ \\
15 & & $(35)$ \\
16 & & $(36)$ \\
9 & & $(3)$ \\
\hline
\end{tabular}

The table shows the youngest individuals diagnosed with $S D H B$-related tumours reported in the literature, grouped by tumour type/location. GIST, gastrointestinal stromal tumour; HNPGL, head and neck paraganglioma; PGL, paraganglioma; PPGL, phaeochromocytoma and paraganglioma; RCC, renal cell carcinoma.

carriers and the follow-up surveillance of patients with known or previous PPGL with regard to balancing the risks and benefits of the modality of imaging used. This is particularly important in individuals who have a risk of tumour recurrence at the primary site and a higher risk of metastatic disease (3).

The acceptability of the surveillance protocol is a further consideration. Although lengthy, MRI scanning is attractive as it is associated with no radiation exposure. Young children may not tolerate long durations of time in a scanner and general anaesthesia is probably not justified for routine screening purposes. Some centres advocate the use of rapid sequence MRI (31) and this could be a viable alternative for paediatric patients. As lifelong surveillance is currently recommended, it is important to balance the need for medical intervention against the potential to provoke unnecessary distress or anxiety as this may adversely affect future engagement with surveillance screening.

Based on our data and the available published literature, we suggest a comprehensive surveillance protocol for paediatric asymptomatic SDHB mutation carriers (Fig. 1). Once a tumour is identified, further imaging for characterisation and management planning and subsequent surveillance follow up needs to be individualised. To be fully effective, a surveillancescreening programme should commence before the earliest known age of disease onset. Hence, we recommend that screening commences at age 5 years, as the earliest reported PPGL disease is at age 6 years (23). The authors recognise that this is an arbitrary age cut-off and needs to be regularly reviewed as more data become available. Consistent with the Endocrine Society guidelines, our screening protocol includes regular clinical assessment, education regarding symptoms of catecholamine excess, measurement of metanephrines and imaging (30). At all ages, it is recognised that the abdomen is the most common site of disease in $S D H B$ carriers $(3,8,13,32)$. Our paediatric data is consistent with this, as all of the asymptomatic carriers who developed tumours and half of the index cases were found to have abdominal PGLs. This is corroborated by analysing the paediatric subgroups in previous studies demonstrating the vast majority of $S D H B$-related tumours in the paediatric age range were abdominal $(3,8,13,18,33)$. Hence, annual abdominal imaging is commenced from the age of 5 years. Ideally MRI would be performed for surveillance in all individuals;

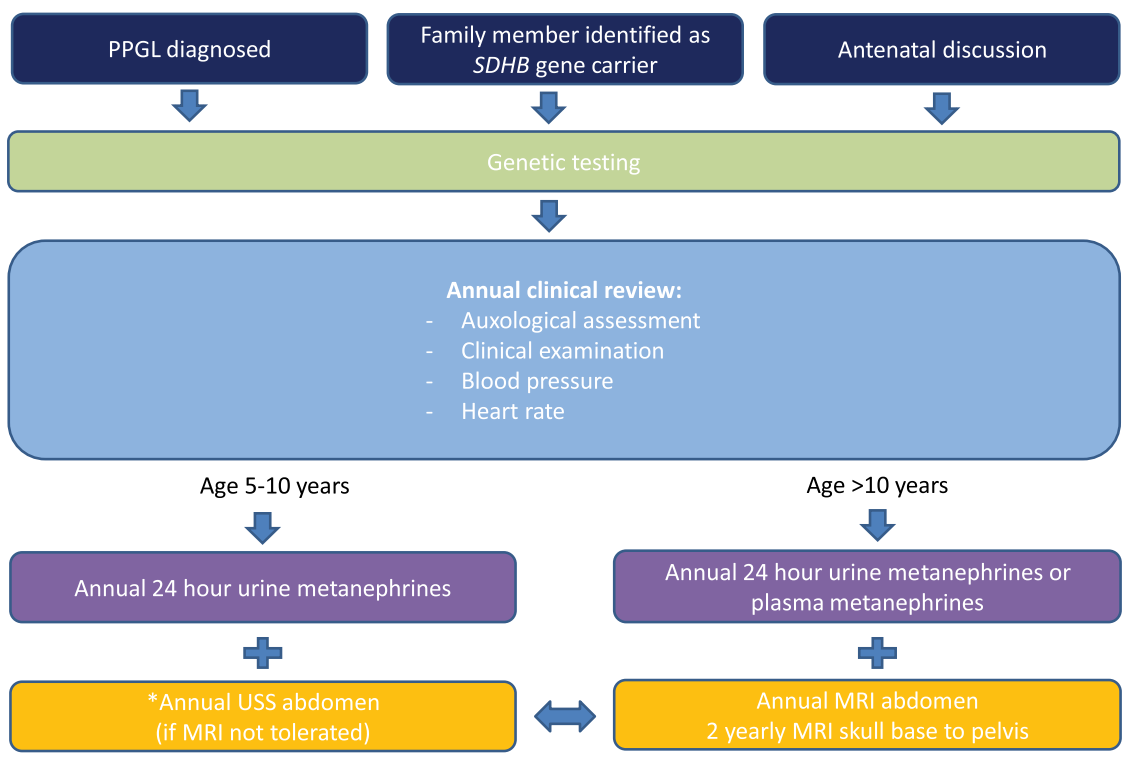

\section{Figure 1}

Our suggested protocol for surveillance screening of asymptomatic paediatric SDHB gene carriers. The figure outlines our suggested surveillance protocol for asymptomatic SDHB gene carriers in the paediatric population based on our data and the available published literature. It shows the different routes by which children are referred for genetic testing, and what should be included in their annual clinical review depending on the age of the child. *However, it should be noted that this protocol should be adapted depending on the maturity of the individual child and the families' wishes. https://ec.bioscientifica.com https://doi.org/10.1530/EC-18-0522 (c) 2019 The authors Published by Bioscientifica Ltd

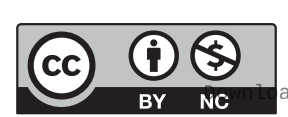

This work is licensed under a Creative Commons Attribution-NonCommercial 4.0 International License. ded from Bioscientifica.com at 04/26/2023 04:08:10AM 
however, as MRI may not be tolerated in younger children, we suggest abdominal US scanning as a possible alternative in asymptomatic patients aged 5-10 years (with normal biochemistry). However, it is important to recognise the limitations of US scanning, particularly its lower sensitivity and specificity for tumour detection (although generally higher in children than adults due to slimmer body habitus), so MRI should be introduced as early as is tolerated, without the need to subject the child to the risk of GA or inducing unnecessary anxiety. As MRI has a much higher sensitivity for detecting tumours compared to US, we recommend from the age of 10 years, or earlier if tolerated, annual non-contrast MRI of neck, thorax, abdomen, thorax and pelvis alternating with abdominal MRI are performed, in line with our adult protocol (11). The rationale for this is that the earliest reported $S D H$-related disease at body sites other than the abdomen is aged 9 years $(19,34,35,36)$. If metanephrines are raised and abdominal imaging does not identify the tumour, other body sites should be investigated. Given the high reported malignancy rate of paediatric PPGLs (3) and the limited data available in childhood, we are currently performing annual imaging in addition to detailed clinical review. However, we expect that this will be extended to 18-24 monthly in line with adult protocol(s), as more data is reported.

Despite the relatively low penetrance of $S D H B$ disease in children and adolescents, the associated tumours cause significant morbidity and mortality, and therefore the authors believe that regular surveillance is warranted. The authors believe that all children that are identified as $S D H B$ carriers should be entered into prospective surveillance programmes. The aim of any $S D H B$ surveillance programme must be to identify disease early, improve cure rates and limit the chance of malignant transformation. Surveillance programmes have inherent drawbacks including the cost burden/ resource constraints to the health system and also anxiety/inconvenience to the patients. Any screening programme risks turning otherwise well and healthy individuals into patients. The surveillance programme for $S D H B$ mutation carriers should begin before the risk of tumour formation. Tumours would then be identified and resected in a timely fashion, perhaps even before they become secretory.

\section{Supplementary data}

This is linked to the online version of the paper at https://doi.org/10.1530/ EC-18-0522.

\section{Declaration of interest}

The authors declare that there is no conflict of interest that could be perceived as prejudicing the impartiality of the research reported.

\section{Funding}

N T is funded by a grant from The Medical College of St Bartholomew's Hospital Trust (registered charity number 1115519).

\section{Ethics statement}

This study was carried out in accordance with the Declaration of Helsinki and all the applicable local regulations. As this is an analysis on subjects' data taken during normal clinical practice, no specific authorisation by ethic committee was sought.

\section{Author contribution statement}

N T and L S collated the data. L M, S A A, W M D and H L S have clinical care of the patients. All authors contributed to the writing of the manuscript.

\section{References}

1 Bauters C, Vantyghem MC, Leteurtre E, Odou MF, Mouton C, Porchet N, Wemeau JL, Proye C \& Pigny P. Hereditary phaeochromocytomas and paragangliomas: a study of five susceptibility genes. Journal of Medical Genetics 200340 e75. (https:// doi.org/10.1136/jmg.40.6.e75)

2 Astuti D, Latif F, Dallol A, Dahia PL, Douglas F, George E, Skoldberg F, Husebye ES, Eng C \& Maher ER. Gene mutations in the succinate dehydrogenase subunit SDHB cause susceptibility to familial pheochromocytoma and to familial paraganglioma. American Journal of Human Genetics 200169 49-54. (https://doi.org/10.1086/321282)

3 King KS, Prodanov T, Kantorovich V, Fojo T, Hewitt JK, Zacharin M, Wesley R, Lodish M, Raygada M, Gimenez-Roqueplo AP, et al. Metastatic pheochromocytoma/paraganglioma related to primary tumor development in childhood or adolescence: significant link to SDHB mutations. Journal of Clinical Oncology 201129 4137-4142. (https://doi.org/10.1200/JCO.2011.34.6353)

4 Babic B, Patel D, Aufforth R, Assadipour Y, Sadowski SM, Quezado M, Nilubol N, Prodanov T, Pacak K \& Kebebew E. Pediatric patients with pheochromocytoma and paraganglioma should have routine preoperative genetic testing for common susceptibility genes in addition to imaging to detect extra-adrenal and metastatic tumors. Surgery 2017161 220-227. (https://doi.org/10.1016/j. surg.2016.05.059)

5 Amar L, Bertherat J, Baudin E, Ajzenberg C, Bressac-de Paillerets B, Chabre O, Chamontin B, Delemer B, Giraud S, Murat A, et al. Genetic testing in pheochromocytoma or functional paraganglioma. Journal of Clinical Oncology 200523 8812-8818. (https://doi.org/10.1200/ JCO.2005.03.1484)

6 Favier J, Amar L \& Gimenez-Roqueplo AP. Paraganglioma and phaeochromocytoma: from genetics to personalized medicine. Nature Reviews Endocrinology 201511 101-111. (https://doi.org/10.1038/ nrendo.2014.188)

7 Darr R, Lenders JW, Hofbauer LC, Naumann B, Bornstein SR \& Eisenhofer G. Pheochromocytoma - update on disease management. Therapeutic Advances in Endocrinology and Metabolism 20123 11-26. (https://doi.org/10.1177/2042018812437356)

8 Neumann HP, Pawlu C, Peczkowska M, Bausch B, McWhinney SR, Muresan M, Buchta M, Franke G, Klisch J, Bley TA, et al. Distinct clinical features of paraganglioma syndromes associated with SDHB
This work is licensed under a Creative Commons Attribution-NonCommercial 4.0 International License. ded from Bioscientifica.com at 04/26/2023 04:08:10AM 
and SDHD gene mutations. JAMA 2004292 943-951. (https://doi. org/10.1001/jama.292.8.943)

9 Rednam SP, Erez A, Druker H, Janeway KA, Kamihara J, Kohlmann WK, Nathanson KL, States LJ, Tomlinson GE, Villani A, et al. Von Hippel-Lindau and hereditary pheochromocytoma/ paraganglioma syndromes: clinical features, genetics, and surveillance recommendations in childhood. Clinical Cancer Research 201723 e68-e75. (https://doi.org/10.1158/1078-0432.CCR-17-0547)

10 Wall BF, Haylockm R, Jansen JTM, Hillier MC, Hart D \& Shrimpton PC. HPA-CRCE-028. Radiation risks from medical X-ray examinations as a function of the age and sex of the patient, pp. 6-12. Didcot, UK: Health Protection Agency, 2011.

11 Tufton N, Shapiro L, Srirangalingam U, Richards P, Sahdev A, Kumar AV, McAndrew L, Martin L, Berney D, Monson J, et al. Outcomes of annual surveillance imaging in an adult and paediatric cohort of succinate dehydrogenase B mutation carriers. Clinical Endocrinology 201786 286-296. (https://doi.org/10.1111/ cen.13246)

12 Srirangalingam U, Walker L, Khoo B, MacDonald F, Gardner D, Wilkin TJ, Skelly RH, George E, Spooner D, Monson JP, et al. Clinical manifestations of familial paraganglioma and phaeochromocytomas in succinate dehydrogenase $\mathrm{B}$ (SDH-B) gene mutation carriers. Clinical Endocrinology 200869 587-596. (https://doi.org/10.1111/ j.1365-2265.2008.03274.x)

13 Timmers HJ, Kozupa A, Eisenhofer G, Raygada M, Adams KT, Solis D, Lenders JW \& Pacak K. Clinical presentations, biochemical phenotypes, and genotype-phenotype correlations in patients with succinate dehydrogenase subunit B-associated pheochromocytomas and paragangliomas. Journal of Clinical Endocrinology and Metabolism 200792 779-786. (https://doi.org/10.1210/jc.2006-2315)

14 Schiffman JD. No child left behind in SDHB testing for paragangliomas and pheochromocytomas. Journal of Clinical Oncology 201129 4070-4072. (https://doi.org/10.1200/JCO.2011.37.8695)

15 Amar L, Servais A, Gimenez-Roqueplo AP, Zinzindohoue F, Chatellier G \& Plouin PF. Year of diagnosis, features at presentation, and risk of recurrence in patients with pheochromocytoma or secreting paraganglioma. Journal of Clinical Endocrinology and Metabolism 200590 2110-2116. (https://doi.org/10.1210/jc.20041398)

16 Badenhop RF, Jansen JC, Fagan PA, Lord RS, Wang ZG, Foster WJ \& Schofield PR. The prevalence of SDHB, SDHC, and SDHD mutations in patients with head and neck paraganglioma and association of mutations with clinical features. Journal of Medical Genetics 200441 e99. (https://doi.org/10.1136/jmg.2003.011551)

17 Pham TH, Moir C, Thompson GB, Zarroug AE, Hamner CE, Farley D, van Heerden J, Lteif AN \& Young WF Jr. Pheochromocytoma and paraganglioma in children: a review of medical and surgical management at a tertiary care center. Pediatrics 2006118 1109-1117. (https://doi.org/10.1542/peds.2005-2299)

18 Benn DE, Gimenez-Roqueplo AP, Reilly JR, Bertherat J, Burgess J, Byth K, Croxson M, Dahia PL, Elston M, Gimm O, et al. Clinical presentation and penetrance of pheochromocytoma/paraganglioma syndromes. Journal of Clinical Endocrinology and Metabolism 200691 827-836. (https://doi.org/10.1210/jc.2005-1862)

19 Ricketts CJ, Forman JR, Rattenberry E, Bradshaw N, Lalloo F, Izatt L, Cole TR, Armstrong R, Kumar VK, Morrison PJ, et al. Tumor risks and genotype-phenotype-proteotype analysis in 358 patients with germline mutations in SDHB and SDHD. Human Mutation 201031 41-51. (https://doi.org/10.1002/humu.21136)

20 Schiavi F, Milne RL, Anda E, Blay P, Castellano M, Opocher G, Robledo M \& Cascon A. Are we overestimating the penetrance of mutations in SDHB? Human Mutation 201031 761-762. (https://doi. org/10.1002/humu.21269)

21 Villani A, Tabori U, Schiffman J, Shlien A, Beyene J, Druker H, Novokmet A, Finlay J \& Malkin D. Biochemical and imaging surveillance in germline TP53 mutation carriers with Li-Fraumeni syndrome: a prospective observational study. Lancet Oncology 2011 12 559-567. (https://doi.org/10.1016/S1470-2045(11)70119-X)

22 Cascon A, Landa I, Lopez-Jimenez E, Diez-Hernandez A, Buchta M, Montero-Conde C, Leskela S, Leandro-Garcia LJ, Leton R, RodriguezAntona C, et al. Molecular characterisation of a common SDHB deletion in paraganglioma patients. Journal of Medical Genetics 2008 45 233-238. (https://doi.org/10.1136/jmg.2007.054965)

23 Imamura H, Muroya K, Tanaka E, Konomoto T, Moritake H, Sato T, Kimura N, Takekoshi K \& Nunoi H. Sporadic paraganglioma caused by de novo SDHB mutations in a 6-year-old girl. European Journal of Pediatrics 2016175 137-141. (https://doi.org/10.1007/s00431-0152614-5)

24 Eisenhofer G, Lenders JW, Goldstein DS, Mannelli M, Csako G, Walther MM, Brouwers FM \& Pacak K. Pheochromocytoma catecholamine phenotypes and prediction of tumor size and location by use of plasma free metanephrines. Clinical Chemistry $2005 \mathbf{5 1}$ 735-744. (https://doi.org/10.1373/clinchem.2004.045484)

25 Timmers HJ, Pacak K, Huynh TT, Abu-Asab M, Tsokos M, Merino MJ, Baysal BE, Adams KT \& Eisenhofer G. Biochemically silent abdominal paragangliomas in patients with mutations in the succinate dehydrogenase subunit B gene. Journal of Clinical Endocrinology and Metabolism 200893 4826-4832. (https://doi.org/10.1210/jc.2008-1093)

26 Tufton N, Sahdev A \& Akker SA. Radiological surveillance screening in asymptomatic succinate dehydrogenase mutation carriers. Journal of the Endocrine Society 20171 897-907. (https://doi.org/10.1210/ js.2017-00230)

27 Stichting Opsporing Erfelijke Tumoren. Dutch guideline for detecting hereditary tumors 2010. Leiden, the Netherlands: StOET, 2010. (available at: https://www.stoet.nl)

28 Kirmani S \& Young WF. Hereditary paragangliomapheochromocytoma syndromes. In GeneReviews. Eds RA Pagon, MP Adam, HH Ardinger, SE Wallace, A Amemiya, LJH Bean. Seattle, WA USA: Univeristy of Washington, 2014. (available at: https://www. ncbi.nlm.nih.gov/books/NBK1548/)

29 Eijkelenkamp K, Osinga TE, de Jong MM, Sluiter WJ, Dullaart RP, Links TP, Kerstens MN \& van der Horst-Schrivers AN. Calculating the optimal surveillance for head and neck paraganglioma in SDHBmutation carriers. Familial Cancer 201716 123-130. (https://doi. org/10.1007/s10689-016-9923-3)

30 Lenders JW, Duh QY, Eisenhofer G, Gimenez-Roqueplo AP, Grebe SK, Murad MH, Naruse M, Pacak K, Young WF, Jr \& Endocrine Society. Pheochromocytoma and paraganglioma: an endocrine society clinical practice guideline. Journal of Clinical Endocrinology and Metabolism 201499 1915-1942. (https://doi.org/10.1210/jc.20141498)

31 Daniel E, Jones R, Bull M \& Newell-Price J. Rapid-sequence MRI for long-term surveillance for paraganglioma and phaeochromocytoma in patients with succinate dehydrogenase mutations. European Journal of Endocrinology 2016175 561-570. (https://doi.org/10.1530/ EJE-16-0595)

32 Papathomas TG, Gaal J, Corssmit EP, Oudijk L, Korpershoek E, Heimdal K, Bayley JP, Morreau H, van Dooren M, Papaspyrou K, et al. Non-pheochromocytoma (PCC)/paraganglioma (PGL) tumors in patients with succinate dehydrogenase-related PCC-PGL syndromes: a clinicopathological and molecular analysis. European Journal of Endocrinology 2014170 1-12. (https://doi.org/10.1530/EJE-13-0623)

33 Niemeijer ND, Rijken JA, Eijkelenkamp K, van der HorstSchrivers ANA, Kerstens MN \& Tops CM, van Berkel A, Timmers HJ, Kunst HPM, Leemans CR, et al. The phenotype of SDHB germline mutation carriers; a nationwide study. European Journal of Endocrinology $2017 \mathbf{1 7 7} 115-125$

34 Cascon A, Pita G, Burnichon N, Landa I, Lopez-Jimenez E, MonteroConde C, Leskela S, Leandro-Garcia LJ, Leton R, Rodriguez-Antona C, et al. Genetics of pheochromocytoma and paraganglioma in Spanish patients. Journal of Clinical Endocrinology and Metabolism 200994 1701-1705. (https://doi.org/10.1210/jc.2008-2756)

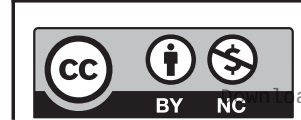


35 Ricketts CJ, Shuch B, Vocke CD, Metwalli AR, Bratslavsky G, Middelton L, Yang Y, Wei MH, Pautler SE, Peterson J, et al. Succinate dehydrogenase kidney cancer: an aggressive example of the Warburg effect in cancer. Journal of Urology 2012188 2063-2071. (https://doi. org/10.1016/j.juro.2012.08.030)
36 Boikos SA, Xekouki P, Fumagalli E, Faucz FR, Raygada M, Szarek E, Ball E, Kim SY, Miettinen M, Helman LJ, et al. Carney triad can be (rarely) associated with germline succinate dehydrogenase defects. European Journal of Human Genetics 201624 569-573. (https://doi. org/10.1038/ejhg.2015.142)

Received in final form 22 January 2019

Accepted 28 January 2019

Accepted Preprint published online 29 January 2019 